\title{
Molecular Screening for E255K and F359V Mutations in Non-Responders Iraqi Chronic Myeloid Leukemia Patients to Imatinib Mesylate Therapy
}

\author{
Qudus W. Jamal ${ }^{1}$, Maysaa A. R. Dhahi ${ }^{1} \&$ Bassam F. Mattii $^{2}$ \\ ${ }^{1}$ Medical Microbiology Department, College of Medicine, Al Nahrain University, Baghdad, Iraq \\ ${ }^{2}$ Hematology unit, Baghdad teaching Hospital, Medical city, Baghdad, Iraq \\ Correspondence : Maysaa A.R. Dhahi, Medical Microbiology Department, College of Medicine, Al-Nahrain \\ University, Baghdad, Iraq. P.O. Box 70062. Tel: 964-790-173-6316. E-mail: dr_maysaa@yahoo.com
}

\author{
Received: July 31, 2014 Accepted: August 14, 2014 Online Published: September 20, 2014 \\ doi:10.5539/ijb.v6n4p139 URL: http://dx.doi.org/10.5539/ijb.v6n4p139
}

\begin{abstract}
Mutations in the kinase domain (KD) of BCR-ABL are the most prevalent mechanism of acquired resistance to first generation of tyrosine kinase inhibitor Imatinib Mesylate (IM) in chronic myeloid leukemia (CML) patients. Dasatinib and Nilotinib, the second generation of tyrosine kinase inhibitors (SGTKI), have been approved for second-line treatment of CML patients who demonstrate resistance to IM. The identification of E255K and F359Vmutations, which are considered highly resistant to SGTKI nilotinib, lead to a clear-cut decision in the choice of the appropriate SGTKI dasatinib. The aim of this study is to assess the frequency of mutations E255K and F359V in Iraqi CML patients who showed criteria of failure or suboptimal response to IM by using Allele Specific Oligonucleotid-Polymerase Chain Reaction (ASO-PCR). In this cross-section study, 70 patients were diagnosed clinically and hematologically as CML, who attended the Baghdad Medical City /Teaching Hospital/Hematology Unite, during the period between September 2011 to June 2012. They were on IM in different doses (400-800 mg/day) for at least one and a half year. Those patients were classified according to their responsiveness to IM into four groups according to European Leukemia Net. Also, 10 healthy age match subjects were included who served as technical negative control. Peripheral blood (PB) samples were taken from each subject. DNA was extracted using commercial available DNA extraction kit. Molecular screening for the presence of E255K and F359V mutations were done using ASO-PCR. The mean value of age of CML patients was $40.5 \pm 2.56$ years. Male to female ratio of CML patients was 1.12:1. The result of molecular screening for two mutations showed that all seventy CML patients were negative for both mutations. We conclude that the presence of other variants of studied mutations, another types of point mutations or other mechanisms for resistance to IM such as over expression of BCR-ABL, drug influx and efflux could be the causes of IM resistance.
\end{abstract}

Keywords: chronic myeloid leukemia, imatinib, treatment resistance, allele-specific oligonucleotide polymerase chain reaction

\section{Introduction}

Chronic myeloid leukemia (CML) is a clonal disease that results from an acquired genetic change in pluripotential hematopoietic stem cells. This altered stem cell proliferates and generates a population of differentiated cells that gradually displace normal haemopoeisis and leads to greatly expanded total myeloid mass. The hallmark of this disease is a unique chromosome, known as the Philadelphia chromosome $(\mathrm{Ph})$, which is found in $95 \%$ of $\mathrm{CML}$ patients (Goldman \& Melo, 2003; Vaidya, Ghosh \& Vundinti, 2011). The current management of CML has been essentially transformed by the introduction of targeted therapy in the form of selective tyrosine kinase inhibitor (TKI). CML patients outcomes have dramatically improved to the extent that first line-TKI, imatinib mesylate (IM), which is considered as the first-line agent for nearly all patients presenting with CML, regardless the phase of the disease. Impressive clinical response is obtained in the majority of patients in chronic phase (CP). However, the clinical response in a number of patients will not be sustained and approximately $20 \%$ to $40 \%$ of patients expressed drug resistance (Milojkovic \& Apperely, 2009). Development of resistance to IM and other TKIs is believed to be a consequence of the interaction of multiple factors including, kinase domain mutations, mutations outside KD, treatment compliance, bioavailability, pharmacodynamics and genetic changes (Quintas-Cardama, 
Kantarjian \& Cortes, 2009). Mutations within the KD of BCR-ABL account for $30 \%$ to $50 \%$ of IM resistance cases. Point mutations that change the amino acid of the contact site or the specific KD conformation to which IM binds attenuate it inhibitory property (Cang \& Liu, 2008). More than 100 point mutations have been reported (OHare, Eide \& Deininger, 2007; Cang \& Liu, 2008). Some of these mutations have important role to clinician in the decision of change treatment from IM to SGTKIs, such as (E255K/V, F359V/I/C). Mutations are less sensitive to nilotinib and sensitive to dasatinib, and that can give idea about the importance to look for these mutations after IM failure or suboptimal response to IM (Tatar et al., 2011; Wongboonma, Thongnoppakhun, \& Auewaraku, 2011). Screening for BCR-ABL mutations could be done using several molecular methods (Deininger et al., 2004; Soverini et al., 2004; Kang et al., 2006; Ernst et al., 2009; Jones et al., 2009). Allele Specific oligonucleotides-Polymerase chain reaction (ASO-PCR) is considered as a very sensitive $(0.5 \%)$ (Wongboonma, Thongnoppakhun \& Auewaraku, 2011) and rapid method used for monitoring CML patients who fail to respond to TKIs or lose their responsiveness (Kang et al., 2006; Ernst et al., 2009).

\section{Methods}

\subsection{Patients and Controls}

In this cross-section study, seventy patients were recruited from Baghdad Medical City/Hematology Unite, in the period between September 2011 to June 2012. They were diagnosed clinically and hematologically as CML. Patients were classified according to their responsiveness to IM into four groups according to European Leukemia Net (ELN 2009) (Baccarani, Cortes, \& Pane, 2009): 1-Failure group which included 22 patients, whose florescence in situ hybridization (FISH) for BCR-ABL gene was more than $35 \%$ despite normal WBCs count while using IM (600-800 mg/day) for at least one and a half year. 2-Suboptimal responders group which included 16 patients, whose FISH for BCR-ABL gene was reading $1-35 \%$ with normal WBCs count and they were on IM for one and a half year. 3-Advanced disease group (patients in accelerated phase or Blast crisis) which included14 patients, those patients have high WBCs count and blast cells more than $10 \%$ in PB and/or bone marrow while using IM $(800 \mathrm{mg} /$ day $)$ for at least one and a half year. 4-Optimal responder which included 18 patients receiving IM $400 \mathrm{mg} /$ day and whose FISH reading is $<1 \%$ with normal WBCs count and they were includes as mutation negative control group. Ten healthy age matched subjects were included in ASO-PCR procedure as healthy negative control. The study protocol was approved by The Ethical Committee of Hematology.

\subsection{Molecular Screening for Resistance Mutations Using ASO-PCR}

DNA was extracted from $300 \mu \mathrm{l}$ PB using DNA isolation kit (Promega, USA) following manufacturer information. Point mutations result in substitution of Glutamine (E) to Lysine (K) at position 255 and Phenyl alanine (F) to Valine (V) at position 359 of BCR-ABL tyrosine kinase were screened by ASO-PCR (Iqbal, Siddiqui, \& Qureshi, 2004). Patient's DNA and DNA from healthy individuals were amplified by using ASO-primers as well as internal control-primers in separate reaction mixtures. Mutation specific primers (ASO) and internal control primers (IC) sequences were given in Table 1. Briefly, three master mixes (each of $30 \mu \mathrm{l}$ ) were prepared, one for mutation E255K detection, the second for mutation F359V detection and third for IC as in the following: 1X PCR buffer, $200 \mu \mathrm{M}$ of dNTPs (promega, USA), 25 pmol of each primers, $1.5 \mathrm{U} /$ reaction of Taq DNA polymerase (Promega, USA). Then, $2 \mu \mathrm{l}$ (equivalent to 100ng) of DNA was added for each ASO reaction tube and IC reaction tube. PCR reaction tubes were transferred to thermal cycler (Eppendorf-thermal cycler, Germany), which was programmed as following: pre-denaturation at $94{ }^{\circ} \mathrm{C}$ for 4 minutes (X1), $\left\{95^{\circ} \mathrm{C}\right.$ for 2 minutes, $63{ }^{\circ} \mathrm{C}$ for E255K or $60{ }^{\circ} \mathrm{C}$ for F359V,for 1 minutes, $72{ }^{\circ} \mathrm{C}$ for 1 minutes $\}$ (X30) and final extension at $72{ }^{\circ} \mathrm{C}$ for 10 minutes (X1). PCR products were electrophoresed in $2.5 \%$ agarose gel.

\subsection{Results Interpretation}

Expected results are PCR products of 453 bp in positive reaction of E255K, 345 bp in positive reaction of F359V and $158 \mathrm{bp}$ in reaction of IC.

Table 1. Sequences of primers used in ASO-PCR

\begin{tabular}{lll}
\hline Primer type & \multicolumn{1}{c}{ Forward primer $\left(5^{\prime} \rightarrow 3^{\prime}\right)$} & \multicolumn{1}{c}{ Reverse primer $\left(5^{\prime} \rightarrow 3^{\prime}\right)$} \\
\hline E255K-ASO & GCGGGGGCCAGTACGGGA & GCCAATGAAGCCCTCGGAC \\
F359V-ASO & GAGTACCTAGAGAAGAAAAACG & ATGCCCAAAGCTGGCTTTG \\
Internal control (IC) & GCCCCCGTTCTATATCATCAC & GGATGAAGTTTTTCTTCTCCAG \\
\hline
\end{tabular}




\subsection{Statistical Analysis}

Data were analyzed using SPSS program (Statistical package for social Sciences) version 16 and Microsoft Office Excel 2007. Numeric data were expressed as mean \pm SD. ANOVA test was used comparison mean more than 2 groups. Pearsons, $\mathrm{S}$ correlation coefficient was used to test correlation between two numerical variables. $P$ less than 0.05 was considered significant.

\section{Results}

The mean age of CML patients was $40.5 \pm 2.56$ SD years at the diagnosis time, ranging from (25-75) years, Male to female ratio of CML patients was 1.12:1. The mean time of IM treatment was 18 months. The mean of drug dose among different groups of CML patients was the highest in the advanced group $(800 \mathrm{mg} / \mathrm{day})$. The mean of WBCs count among different groups of CML patients were highest in the advanced group patients $(61.06 \pm 10.47) \times 10 / \mathrm{L}$. The mean of FISH reading among different groups of CML patients were highest in the advanced group $74 \%$ as shown in Table 2.

Table 2. The mean of different parameters in different CML patients groups

\begin{tabular}{|c|c|c|c|c|c|}
\hline $\begin{array}{l}\text { Groups of } \\
\text { Patients }\end{array}$ & $\begin{array}{c}\text { Age } \\
\text { (Year) } \\
P=0.021\end{array}$ & $\begin{array}{c}\text { Duration of disease } \\
\text { (Year), } P=\mathbf{0 . 0 0 1}\end{array}$ & $\begin{array}{c}\text { Drug dose } \\
\text { (mg/day) } \\
P=0.001\end{array}$ & $\begin{array}{c}\text { WBCs count } \\
\begin{array}{c}(\times 10 / \mathrm{L}) \\
P=0.001\end{array}\end{array}$ & $\begin{array}{c}\text { FISH } \\
(\%) \\
P=0.001\end{array}$ \\
\hline Failure & 45.5 & 4.97 & 718 & 6.54 & 67.40 \\
\hline Advanced & 37.7 & 5.78 & 800 & 61.06 & 74.00 \\
\hline Suboptimal & 34.6 & 4.68 & 600 & 7.25 & 18.87 \\
\hline Optimal & 43.1 & 7.75 & 400 & 7.75 & 0 \\
\hline
\end{tabular}

Screening analysis for the two resistant mutations E255K and F359V using ASO-PCR technique in all groups of CML patients were negative and no mutations were detected in healthy individuals and optimal responders that were included as disease control group, Figure 1.

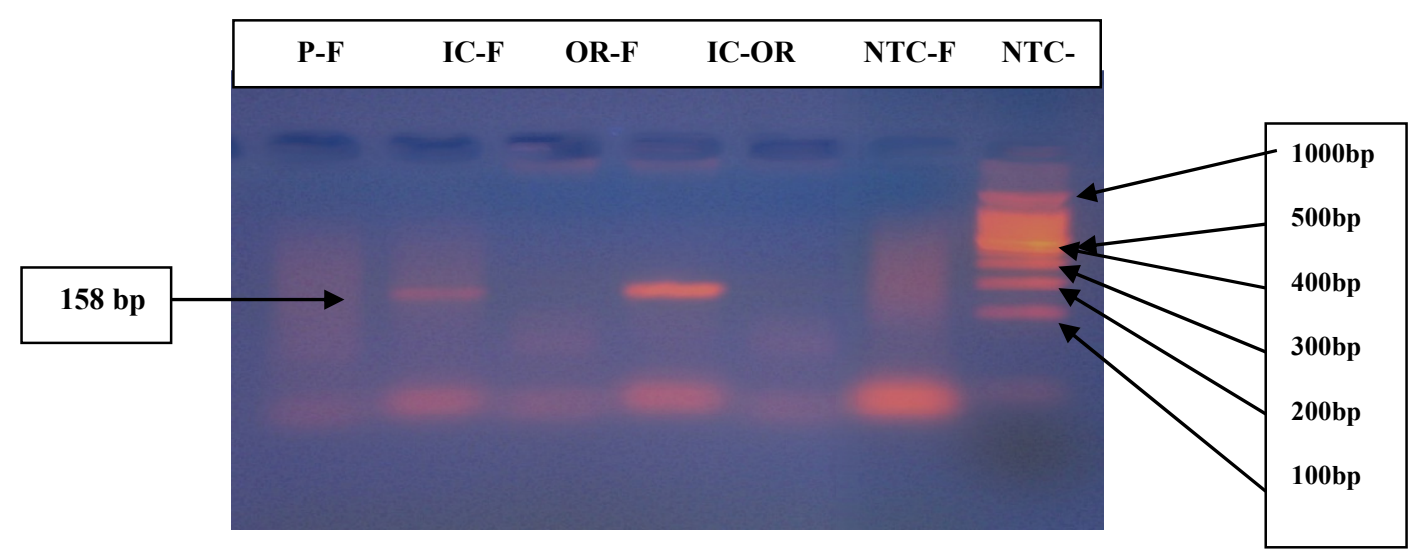

Figure 1. Allele Specific Oligonucleotide-PCR analysis of F359V mutations in CML patients

Lane P-F: PCR amplified product of F359Vmutation using DNA from non-responder CML patient.

Lane OR-F: PCR amplified product of F359Vmutation using DNA from optimal responder CML patient.

Lane IC-OR: Internal control of F359V mutation.

Lane NTC-F: No template control for mutation F359V.

Lane NTC-IC: No template control for internal control.

MW: Molecular weight marker, DNA ladder $100 \mathrm{bp}$.

Electrophoresis was carried in $2.5 \%$ agarose gel at $(3 \mathrm{~V} / \mathrm{cm})$ for 60 minutes. 


\section{Discussion}

Mutations in the kinase domain of BCR-ABL are the most prevalent mechanism of acquired IM resistance in patient with CML. Although the majority of CML patients treated with IM show at least, significant hematologic response, resistance to IM is still a problem, mainly in patients within the accelerated or blast crisis phases of the disease. It has become clear that optimal treatment of patients based on appropriate monitoring of therapeutic effect, which has emerged as a relevant and sensitive part of the therapeutic strategy. The correct monitoring of CML treatment, which include conventional cytogenetic karyotyping, FISH, molecular evaluation of residual disease and the search for BCR-ABL kinase domain mutations, should be performed at regular intervals. Also, response definitions should be standardized (Quintas-Cardama, Kantarjian, \& Cortes, 2009).

In this study, the mean age of CML patients at time of diagnosis was $40.45 \pm 2.56$ years (Mean $\pm \mathrm{SD}$ ), and that consistent with the results obtained by two previous Iraqi studies (AL-Rawi, 2001; Ismail, Yahya, \& Farid, 2003) but another Iraqi study found that the mean age was $34.71 \pm 1.02$ years (Dhahii ,2008).

Moreover the Male to female ratio was 1.12:1 which was consistent with the ratio mentioned by Al-Rawi study (AL-Rawi, 2001) in which the incidence of CML was slightly higher in male than female, but it differs from what was mentioned by Dhahii study1:1.62 (Dhahii, 2008), which is mostly due to the unstable security situation in Iraq in 2006 and 2007 when females could attend hospitals for receiving therapy more than males.

This study focused on two point mutations, E255K and F359V. Neither E255K nor F359V were detected in all of $70 \mathrm{CML}$ patients using ASO-PCR technique. This is consistent with the result obtained by Willis et al study, who did not detect these two mutations in 66 patients by using ASO-PCR technique (Willis et al., 2005). However, Sorel study detected the E255K mutation in only one out of 59 IM resistant patients by using Double-Gradient-Denaturing-Gradient Gel Electrophoresis (Sorel et al., 2005). Another study by Elass, Osman \& AL-Gadir (2011) detected E255K in one patient from 50 IM resistant CML patients by using ASO-PCR technique.

In an Egyptian study, mutation screening was performed by using allele specific oligonucleotide polymerase chain reaction (ASO-PCR) in 42 non-optimal responders; 28 resistant patients, 44 optimal and suboptimal responders. BCR-ABL mutations were detected in 16/28 resistant patients (57\%) and in none of the 44 optimal or suboptimal responders $(0 \%)$ (Elnahass et al., 2013).

In an Indian study, 4 and 3 cases of E255K and F359V mutations respectively were detected in $100 \mathrm{BCR}-\mathrm{ABL}$ positive imatinib, nilotinib and dasatinib resistant cases (Mitra et al., 2013).

In a Polish study, Direct sequencing analysis of BCR-ABL gene was performed in 92 patients treated with IM for more than 3 months. Co-existence of F359V and Y253F mutations were detected in one patient with lymphoid blast crisis of CML (Lewandowski et al., 2009).

Differences in the frequency of mutation detection may be attributed to several factors; differences in the sensitivities of the techniques, in the time point of analysis, in phase of the disease and eventually due to differences in the genetic make-up of patient populations (Gorre et al., 2001).

Other mechanisms can also cause resistance to imatinib in the absence of mutations in the KD. Wu et al studied LYN kinase (Lck/Yes novel tyrosine kinase), which regulates cell survival, and responsiveness of CML cells to TKIs. The study showed that IM treatment suppresses LYN phosphorylation in cells from IM-sensitive CML patients. Thus, disruption in LYN kinase may be involved in IM resistance in CML patients with BCR-ABL negative mutations (Wu et al., 2008). Apperley et al suggested that drugs influx and efflux may play a role in IM resistance CML patients with TK negative mutations (Apperley, 2007).

\section{References}

AL-Rawi, F. A. R. (2001). Clinical Findings and bone marrow feature in Chronic Myeloid Leukemia. A thesis submitted to the Scientific Council of Pathology.

Apperley, J. F. (2007). Part I: mechanisms of resistance to imatinib in chronic myeloid leukemia. Lancet Onco, 8 , 1018-1029.

Baccarani, M., Cortes, J., \& Pane, F. (2009). Chronic myeloid leukemia: An update of concepts and management recommendations of European Leukemia Net. $J$ Clin Oncol, 27, 6041-6051. http://dx.doi.org/10.1200/JCO.2009.25.0779

Cang, S., \& Liu, D. (2008). P-loop mutation and novel therapeutic approaches for imatinib failure in chronic myeloid leukemia. J Hematology and Onco, 1, 3-20. http://dx.doi.org/10.1186/1756-8722-1-15 
Deininger, M. W., McGreevey, L., Willis, S., Bainbridge, T. M., Druker, B. J., \& Heinrich, M. C. (2004). Detection of ABL kinase domain mutations with denaturing high-performance liquid chromatography. Leukemia, 18, 864-871.

Dhahii, M. A. R. (2008). Molecular, cytogenetic and immunological Detection and Quantification of BCR-ABL Gene and Protein in Chronic Myeloid Leukemia Patients Treated with Imatinib. PhD. Thesis submitted to the Al-Nahrain University, College of Medicine, Microbiology Department.

Elaas, W. A., Osman, I. M., \& AL-Gadir, A. M. (2011). Detection of Imatinib Resistance in Chronic Myeloid Leukemia Using Allele-Specific Oligonucleotide polymerase Chain Reaction in Sudan. Australian $J$ of Basic and Sciences, 5, 86-91.

Elnahass, Y. H., Mahmoud, H. K., Ali, F. T., Mohamed, M. R., Said, M. M., Samra, M. A. M., ... ElMetnawy, W. H. (2013). Abl Kinase Domain Mutations in Imatinib-treated Egyptian Patients with Chronic Myeloid Leukemia. J Leuk, 1, 106. http://dx.doi.org/10.4172/2329-6917.1000106 evels

Ernst T., Gruber, F. X., Pelz-Ackermann, O., Maier, J., Pfirrmann, M., Müller, M. C., ... Lange, T. (2009). BCR-ABL kinase domain mutation on second line dasatinib or nilotinib therapy in chronic myeloid leukemia patient after imatinib failure: a cooperative evaluation of different detection method. $J$ Haematologica, 94, 1227-1253. http://dx.doi.org/10.3324/haematol.2009.006981

Goldman, J. M., \& Melo, J. V. (2003). Chronic Myeloid leukemia-advances in biology and new approach treatment. $N$ Engl J Med, 349, 1451-1464.

Gorre, M. E., Mohammed, M., Ellwood, K., Hsu, N., Paquette, R., Rao, P. N., \& Sawyers, C. L. (2001). Clinical resistance to STI-571 cancer therapy caused by BCR-ABL gene mutation or amplification. Science, 293, 876-880.

Iqbal, Z., Siddiqui, R. T., \& Qureshi, J. A. (2004). Two different mutation in ABL gene ATP binding domain conferring primary resistance in a chronic myeloid leukemia CML patient :A case report. Biol Procef, 6, 144-4. http://dx.doi.org/10.1251/bp083

Ismail, N. I., Yahya, H. I., \& Farid, I. (2003). Chronic myeloid leukemia profiles in medical city. J Fac Med Baghdad, 34, 287-291.

Jones, D., Kamel-Reid, S., Bahler, D., Dong, H., Elenitoba-Johnson, K., Press R., ... Viswanatha, D. (2009). Laboratory practice guidelines for detecting and reporting BCR-ABL drug resistance mutations in chronic myelogenous leukemia and acute lymphoblastic leukemia: a report of the Association for Molecular Pathology. J Mol Diagn, 11, 4-11.

Kang, H. Y., Hwang, J. Y., Kim, S. H., Goh, H. G., Kim, M., \& Kim, D. W. (2006). Comparison of allele specific oligonucleotides-polymerase chain reaction and direct sequencing for high throughput screening of ABL kinase domain mutation in chronic myeloid leukemia resistant to imatinib. Haematologica, 91, 659-662.

Lewandowski, K., Warzocha, K., Hellmann, A., Skotnicki, A., Prejzner, W., Foryciarz, K., ... Komarnicki, M. (2009). Frequency of BCR-ABL gene mutations in Polish patients with chronic myeloid leukemia treated with imatinib, A final report of the MAPTEST study. Pol Arch Med Wewn, 119, 789-794.

Milojkovic, D., \& Apperely, J. (2009). Mechanism of Resistance to imatinib and Second-Generation Tyrosine Inhibitor in Chronic Myeloid Leukemia. Clin Cancer Res, 15, 7519-7525.

Mitra, P., Dasgupta, S., Kumar Basu, C. H., Gharami, F. H., Mandal, S., \& Mukhopadhyay, A. (2013). Study of different mutations in chronic myeloid leukemia in India and their co-relation with drug resistance. $J$ Clin Oncol, 31 (suppl; abstr 7083).

OHare, T., Eide, C. A., \& Deininger, M. W. (2007). Bcr-Abl kinase domain mutations ,drug resistance ,and the road to a cure for chronic myeloid leukemia. Blood, 110, 2242-9. http://dx.doi.org/10.1182/blood-2007 $-03-066936$

Quintas-Cardama, A., Kantarjian, H., \& Cortes, J. (2009). Mechanism of Primary and Secondary Resistance to Imatinib in Chronic Myeloid Leukemia. Cancer Control, 16, 122-131.

Sorel, N., Chazelas, F., Brizard, A., \& Chomel, J. C. (2005). Double-Gradient-Denaturing-Gradient Gel Electrophoresis for Mutation Screening of the BCR-ABL Tyrosine Kinase Domain in Chronic Myeloid Leukemia patient. Clinical Chemistry, 51, 1263-1266. http://dx.doi.org/10.1373/clinchem.2004.047274 
Soverini, S., Martinelli, G., Amabile, M., Poerio, A., Bianchini, M., Rosti, G., ... Baccarani, M. (2004). Denaturing-HPLC-based assay for detection of ABL mutations in chronic myeloid leukemia patients resistant to Imatinib. Clin Chem, 50, 205-1213.

Vaidya, S., Ghosh, K., \& Vundinti, B. R. (2011). Recent development in drug resistance mechanism in chronic myeloid leukemia. E J Haematology, 87, 381-393. http://dx.doi.org/10.1111/j.1600-0609.2011.01689

Willis, S., Lange, T., Demehri, S., Otto, S., Crossman, L., Niederwieser, D., ... Deininger, M. W. (2005). High-sensitivity detection of BCR-ABL kinase domain mutations in imatinib-naive patients: correlation with clonal cytogenetic evolution but not response to therapy. Blood, 106, 2128-2137. http://dx.doi.org/10.1182/blood-2005-03-1036.

Wongboonma, W., Thongnoppakhun, W., \& Auewaraku, C. U. (2011). A single-tube allele specific-polymerase chain reaction to detect T315I resistant mutation in chronic myeloid leukemia patients. J Hematology Oncology, 4, 1-7. http://dx.doi.org/10.1186/1756-8722-4-7

Wu, J., Meng, F., Kong, L. Y., Peng, Z., Ying, Y., Bornmann, W. G., \& Darnay, B. G. (2008). Association Between Imatinib-Resistant BCR-ABL Mutation-Negative Leukemia and Persistent Activation of LYN Kinase. J Natl Cancer Inst, 100, 926- 939. http://dx.doi.org/10.1093/jnci/djn188

\section{Copyrights}

Copyright for this article is retained by the author(s), with first publication rights granted to the journal.

This is an open-access article distributed under the terms and conditions of the Creative Commons Attribution license (http://creativecommons.org/licenses/by/3.0/). 